\title{
Evaluation of the Retrogasserian Opioid Application in the Treatment of Idiopathic Trigeminal Neuralgia
}

\author{
Mustafa Kemal ILIK' , Faik ILIK² \\ ${ }^{1}$ Farabi Hospital, Department of Neurosurgery, Konya, Turkey \\ ${ }^{2}$ KTO Karatay University, Medicana Hospital, Department of Neurology, Konya, Turkey \\ Corresponding author: Mustafa Kemal ILIK mkilik@gmail.com
}

\section{ABSTRACT}

AIM: To evaluate the clinical outcomes of the retrogasserian opioid application in patients with type 1 trigeminal neuralgia.

MATERIAL and METHODS: A total of 37 patients (12 male, 25 female; average age $56.2 \pm 5.4$ years) who were administered retrogasserian opioid due to type 1 trigeminal neuralgia between February 2012 and May 2015 were included in the study. A visual analogue scale was used to evaluate pain at the last preoperative and postoperative visits (median follow-up period: 13 months, mean follow-up period: 15.6 months). All parameters were analysed using Wilcoxon signed-rank and Mann-Whitney $U$ tests, with $\mathrm{p}<0.05$ considered statistically significant.

RESULTS: Visual analogue scale scores of all 37 patients were significantly improved in the postoperative period. The average visual analogue scale scores were $7.9 \pm 0.62$ preoperatively and $2.9 \pm 0.5$ postoperatively. All changes were statistically significant.

CONCLUSION: Percutaneous retrogasserian opioid injection in type 1 trigeminal neuralgia is an effective and safe method of pain control.

KEYWORDS: Trigeminal neuralgia, Gasser ganglion, Bupivacaine, Fentanyl

\section{INTRODUCTION}

A mong cranial neuralgias, trigeminal neuralgia (TN) is the most commonly observed type, with a reported incidence of 5 per 100,000 cases. It was primarily defined by Nicolous Andre in 1756, and its pathophysiology has been studied by various scientists (1).

The pain occurs in an area where the fifth cranial nerve is scattered, and it is characterized by sudden attacks without additional neurological deficits (2). The pain can occur in the first, second, or third branches of the nerve. In addition, it can also be present in several branches of the nerve. It is generally felt as a one-sided pain. Nevertheless, it can also be two-sided $(10,20)$. The TN form accompanying systemic diseases such as multiple sclerosis is referred to as secondary $T N$. The TN form that does not accompany any disease is termed primary or idiopathic TN (11-13).
Recently, TN has been accepted as a neuropathic form of pain. Some irritative pathologies can cause TN in the middle fossa, cavernous cortex, and peripheral area (9).

According to the guidelines of the American Academy of Neurology and the European Federation of Neurological Societies, carbamazepine and oxcarbazepine are recommended as firstline medical treatments for pain control in patients with TN (6). However, minimally invasive treatment methods and surgical treatments can also be applied to patients who do not receive benefit from medical treatments. Minimally invasive treatment methods for TN are percutaneous controlled rhizotomy, glycerol rhizotomy, and percutaneous balloon compression. Surgical treatments are microvascular decompression and gamma knife radiosurgery $(8,12,14,15,18)$.

Opioids are the most effective medical agents that can be used to treat acute and chronic pain. In previous studies, 
they were used in the treatment of intercostal neuralgia that developed after thoracotomy as well as in the sphenopalatine ganglion blockage in type 2 TN $(5,16)$.

In our study, the efficiency of the combination of bupivacaine and fentanyl on the Gasser ganglion blockage in idiopathic TN patients was examined.

\section{- MATERIAL and METHODS}

Ethics committee approval was received for this study from KTO University, Medicana Faculty of Medicine (Decision No. 2018-18). Informed consent forms were obtained from all patients.

In our retrospective study, recordings of 37 patients who were administered due to type 1 TN between February 2012 and May 2015 were examined. There were 12 male and 25 female patients. Sixty percent of the patients had pain on the right side, and $40 \%$ had pain on the left side.

Blockage treatment was administered to patients who had been under carbamazepine treatment more than 2 years and who were evaluated as normal according to results from brain magnetic resonance imaging. Visual analogue scale (VAS) scores obtained preoperatively and at the last visit were recorded.

\section{Surgical Procedure}

The patient was placed in the supine position. A thin roll was placed under the patient's head, and the patient was brought to 15 degrees of extension. The patient was lightly sedated with propofol. The patient's blood pressure, blood oxygen saturation, and cardiac function were monitored. The perioral area was sterilized. Local anaesthesia was administered with lidocaine at the entry point of the cannula, $2.0 \mathrm{~cm}$ lateral of the labial commissure. Using a 30-gauge long dental needle, the tip was directed to the intersection of the plane passing through the pupil and the plane passing parallel to the $\sim 2.0 \mathrm{~cm}$ lateral area of the meatus acusticus externus. It was noted that the needle did not perforate the oral mucosa. The needle was directed toward the foramen ovale, and continuous images were taken using fluoroscopy to visualize its position. Because the preganglionic (retrogasser) fibers of the Gasser ganglion were at the level of the petroclival angle, it was noted that the needle did not go beyond this point. After the appearance of cerebrospinal fluid (CSF), $3 \mathrm{~mL}$ of local anaesthetic agent consisting of $2 \mathrm{cc}$ bupivacaine and $1 \mathrm{~mL}$ prilocaine in addition to $1 \mathrm{~mL}$ fentanyl and $1 \mathrm{~mL}$ betamethasone disodium phosphate Celestone ${ }^{\circledR}$ was injected. After, the needle was removed, and the procedure was ended (Figure 1).

Cold compress application was performed to decrease oedema, which can occur in the chin after the operation. Patients were discharged one day after the operation.

\section{Statistical Analysis}

Statistical analysis was performed using the Wilcoxon signed-rank and Mann-Whitney $U$ tests with the help of the SPSS program (18.0 for Windows). A $p$ value of $<0.05$ was considered statistically significant.

\section{- RESULTS}

Of the 37 patients, 12 were men and 25 were women, and their mean age was $56.2 \pm 5.4$ years. The mean VAS pain scores of patients decreased from $7.9 \pm 0.62$ at the initial presentation to $2.9 \pm 0.5$ at the last postoperative visit $(p<0.01)$. The mean follow-up period was 15.6 months (median: 13 months).

In this series, no mortality or major complications (anaesthesia dolorosa, permanent corneal reflex loss, transient cranial nerve weakness, CSF fistula, meningitis, etc.) were observed. The procedure was repeated twice in 6 patients and 3 times in 2 patients.
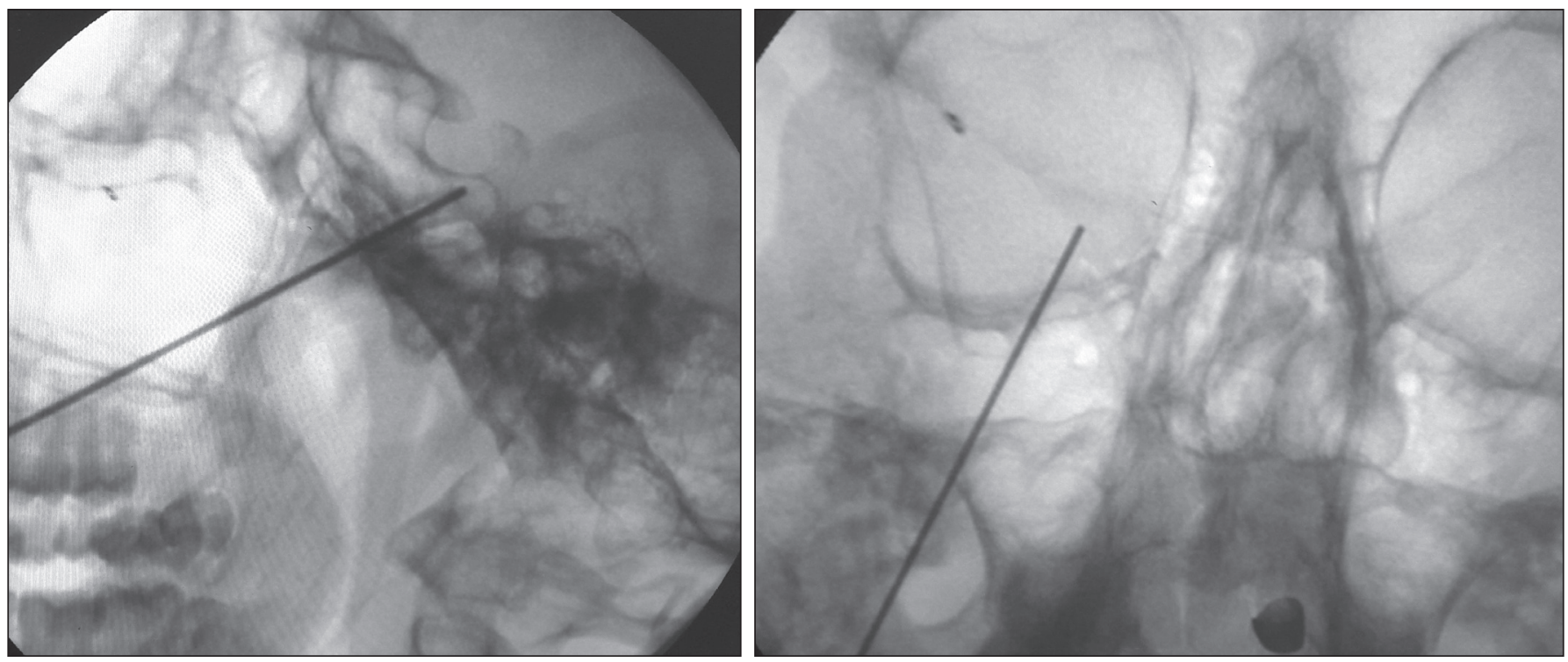

Figure 1: Fluoroscopic images show that the 30-gauge dental needle is in the petroclival angle (Left: Lateral, Right: Anteroposterior). 


\section{DISCUSSION}

TN is a disorder characterized by sudden onset, lightning flash, short duration, and paroxysmal pain attacks in the area of distribution of one or more branches of the trigeminal nerve. There is no cranial nerve or neurological disorder other than pain $(1,4)$. Primary treatment of TN is medical. However, surgical treatment can be performed when medical treatment is inadequate. Percutaneous methods such as glycerol rhizotomy, trigeminal radiofrequency rhizotomy (RFT), and balloon compression can be used (3). Furthermore, surgical methods such as microvascular decompression can also be employed. The choice of the treatment method in TN changes according to the age and general health status of the patient, as well as the severity of the pain and the status of compliance with the medical treatment (19).

The glycerol rhizotomy procedure is performed in trigeminal cisternae by glycerol injection. It is essentially a destructive application. Its pain control is inadequate; however, the complication rate is higher $(7,21)$. RFT is based on the principle that the slowly formed thermal lesion causes damage in trigeminal root pain fibres. Compared with other percutaneous methods, it has been found that the recurrence is less likely and pain control is better. The reason for this is that thermal injury is more effective than chemical and mechanical injuries. However, severe complications such as corneal anaesthesia, anaesthesia dolorosa and neuroparalytic keratitis have been observed after RFT application (10).

Opioids are drugs commonly used in the treatment of acute and chronic pain. Fentanyl is a synthetic opioid and is quite lipophilic. It acts through $\mu$ receptors. Recently, fentanyl has been used as a patch in the treatment of many chronic pain types (17). Furthermore, it has been used for the treatment of type $2 \mathrm{TN}$ in the sphenopalatine ganglion blockade, for which successful outcomes were obtained (5).

In our study, retrogasserian opioid injection was administered to patients with type $1 \mathrm{TN}$. A significant improvement was observed in the VAS pain scores of the patients, and no major complication was noted.

The primary limitation of the present study is its retrospective nature. However, the present findings may contribute to the percutaneous treatment of TN.

\section{CONCLUSION}

This study shows that opioid injection to the gasserian ganglion is an efficient and safe technique in the short and medium term, and it can be efficiently applied to patients with type $1 \mathrm{TN}$.

\section{REFERENCES}

1. Andres $M$ : The pathophysiology of trigemina neuralgia. Lozano PG, Tasker RR (ed), Berlin: Springer, 2009

2. Chen JF, Tu PH, Lee ST: Long-term follow-up of patients treated with percutaneous balloon compression for trigeminal neuralgia in Taiwan. World Neurosurg 76:586-591, 2011
3. Cheng JS, Lim DA, Chang EF, Barbaro NM: A review of percutaneous treatments for trigeminal neuralgia. Neurosurgery 10:25-33, 2014

4. Civelek E, Cansever T, Imer M, Hepgul K, Barlas O: Trigeminal neuralgia and treatment options. Agri 17:19-26, 2005

5. Coven I, Dayisoylu EH: Evaluation of sphenopalatine ganglion blockade via intra oral route for the management of atypical trigeminal neuralgia. Springerplus 5: 906, 2016

6. Cruccu G, Gronseth G, Alksne J, Argoff C, Brainin M, Burchiel $\mathrm{K}$, Nurmikko T, Zakrzewska JM: AAN-EFNS guidelines on trigeminal neuralgia management. European Journal of Neurology 15:1013-1028, 2008

7. Harries AM, Mitchell RD: Percutaneous glycerol rhizotomy for trigeminal neuralgia: Safety and eff icacy of repeat procedures. Br J Neurosurg 25:268-272, 2011

8. Hitchon PW, Holland M, Noeller J, Smith MC, Moritani T, Jerath $\mathrm{N}, \mathrm{He} \mathrm{W}$ : Options in treating trigeminal neuralgia: Experience with 195 patients. Clin Neurol Neurosurg 149:166-170, 2016

9. Huang Q, Liu X, Chen J, Bao C, Liu D, Fang Z, Liang X, Lu $Z$, Wan L: The effectiveness and safety of thermocoagulation radiofrequency treatment of the ophthalmic division (V1) and/ or maxillary (V2) and mandibular (V3) division in idiopathic trigeminal neuralgia: An observational study. Pain Physician 19:1041-1047, 2016

10. Kanpolat Y, Savas A, Bekar A, Berk C: Percutaneous controlled radiofrequency trigeminal rhizotomy for the treatment of idiopathic trigeminal neuralgia: 25-year experience with 1,600 patients. Neurosurgery 48:524-532, 2001

11. Kouzounias K, Schechtmann G, Lind G, Winter J, Linderoth $B$ : Factors that influence outcome of percutaneous balloon compression in the treatment of trigeminal neuralgia. Neurosurgery 67:925-934, 2010

12. Montano N, Papacci F, Cioni B, Di Bonaventura R, Meglio M: The role of percutaneous balloon compression in the treatment of trigeminal neuralgia recurring after other surgical procedures. Acta Neurol Belg 114:59-64, 2014

13. Mullan S, Lichtor T: Percutaneous microcompression of the trigeminal ganglion for trigeminal neuralgia. J Neurosurg 59:1007-1012, 1983

14. Reddy VK, Parker SL, Patrawala SA, Lockney DT, Su PF, Mericle RA: Microvascular decompression for classic trigeminal neuralgia: Determination of minimum clinically important diff erence in pain improvement for patient reported outcomes. Neurosurgery 72:749-754, 2013

15. Regis J, Tuleasca C: Fifteen years of Gamma Knife surgery for trigeminal neuralgia in the Journal of Neurosurgery: History of a revolution in functional neurosurgery. J Neurosurg 115:2-7, 2011

16. Savage C, McQuitty C, Wang D, Zwischenberger JB: Postthoracotomy pain management. Chest Surg Clin N Am 12:251-263, 2002

17. Sivakumar W, Karsy M, Brock A, Schmidt RH: Postoperative pain control with the fentanyl patch and continuous paravertebral anesthetic infusion after posterior occipitocervical junction surgery. Cureus 17:e645,2016 
18. Song ZX, Qian W, Wu YQ, Sun FJ, Fei J, Huang RS, Fang JY, Wu CZ, An YM, Wang D, Yang J: Effect of gamma knife treatment on the trigeminal nerve root in Chinese patients with primary trigeminal neuralgia. Turk Neurosurgery 24:163-169, 2014

19. Tucer B, Ekici MA, Demirel S, Basarslan SK, Koc RK, Guclu B: Microvascular decompression for primary trigeminal neuralgia: Short-term follow-up results and prognostic factors. J Korean Neurosurg Soc 52:42-47, 2012
20. Tun K, Celikmez R, Gurcan O, Gurcay AG, Turkoglu F, Kaptanoglu E: Idiopathic bilateral trigeminal neuralgia treated by bilateral microvascular decompression. Turk Neurosurg 17:294-296, 2007

21. Xu-Hui W, Chun Z, Guang-Jian S, Min-Hui X, GuangXin C, Yong-Wen Z, Lun-Shan X: Long-term outcomes of percutaneous retrogasserian glycerol rhizotomy in 3370 patients with trigeminal neuralgia. Turk Neurosurgery 21: 4852,2011 